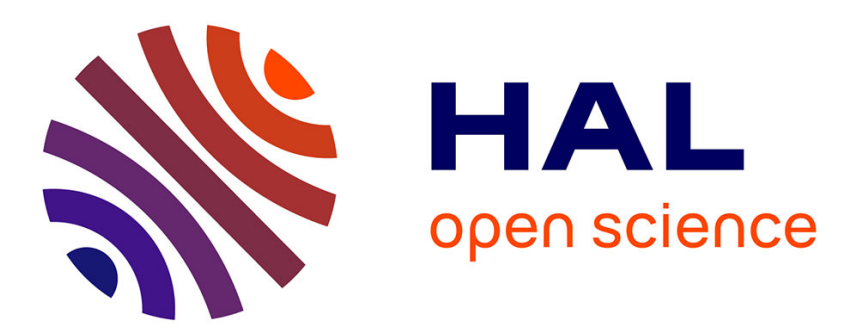

\title{
Independent Control of Adhesive and Bulk Properties of Hybrid Silica Coatings on Polycarbonate
}

\author{
Krystelle Lionti, Linying Cui, Willi Volksen, Reinhold Dauskardt, Geraud
} Dubois, Bérangère Toury

\section{- To cite this version:}

Krystelle Lionti, Linying Cui, Willi Volksen, Reinhold Dauskardt, Geraud Dubois, et al.. Independent Control of Adhesive and Bulk Properties of Hybrid Silica Coatings on Polycarbonate. ACS Applied Materials \& Interfaces, 2013, 5 (21), pp.11276 - 11280. 10.1021/am403506k . hal-01612037

\section{HAL Id: hal-01612037 https://hal.science/hal-01612037}

Submitted on 6 Oct 2017

HAL is a multi-disciplinary open access archive for the deposit and dissemination of scientific research documents, whether they are published or not. The documents may come from teaching and research institutions in France or abroad, or from public or private research centers.
L'archive ouverte pluridisciplinaire HAL, est destinée au dépôt et à la diffusion de documents scientifiques de niveau recherche, publiés ou non, émanant des établissements d'enseignement et de recherche français ou étrangers, des laboratoires publics ou privés. 


\title{
- Independent Control of Adhesive and Bulk Properties of Hybrid Silica Coatings on Polycarbonate
}

\author{
${ }_{3}$ Krystelle Lionti, ${ }^{\dagger}$ Linying Cui, ${ }^{\ddagger}$ Willi Volksen, ${ }^{\dagger}$ Reinhold Dauskardt, ${ }^{*}{ }^{\ddagger}$ Geraud Dubois, $*, \dagger, \dagger$ \\ 4 and Berangere Toury*,\$ \\ $5{ }^{\dagger}$ IBM Almaden Research Center, San Jose, California 95120, United States \\ $6{ }^{\ddagger}$ Department of Materials Science and Engineering, Stanford University, Stanford, California 94305-4034, United States \\ $7{ }^{\S}$ Laboratoire des Multimateriaux et Interfaces, UMR 5615, University of Lyon, Villeurbanne, 69622, France
}

8 ABSTRACT: Transparent polymers are widely used in many 9 applications ranging from automotive windows to micro10 electronics packaging. However, their intrinsic characteristics, 11 in particular their mechanical properties, are significantly 12 degraded with exposure to different weather conditions. For 13 instance, under humid environment or UV-irradiation, 14 polycarbonate (PC) undergoes depolymerization, leading to 15 the release of Bisphenol A, a molecule presumed to be a 16 hormonal disruptor, potentially causing health problems. This 17 is a serious concern and the new REACH (Registration, 18 Evaluation, Authorization and Restriction of Chemical

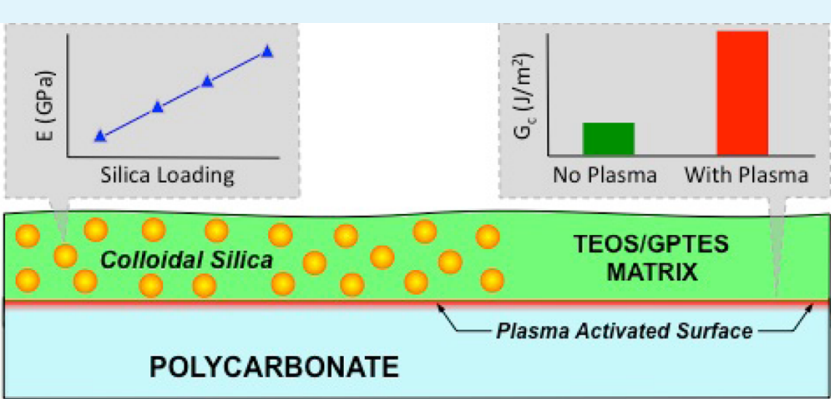
substances ) program dictates that materials releasing Bisphenol A should be removed from the market by January 1st, 2015 (2012-1442 law). Manufacturers have tried to satisfy this new regulation by depositing atop the PC a dense oxide-like protective coating that would act as a barrier layer. While high hardness, modulus, and density can be achieved by this approach, these coatings suffer from poor adhesion to the PC as evidenced by the numerous delamination events occurring under low scratch constraints. Here, we show that the combination of a $\mathrm{N}_{2} / \mathrm{H}_{2}$-plasma treatment of PC before depositing a hybrid organicinorganic solution leads to a coating displaying elevated hardness, modulus, and density, along with a very high adherence to PC $\left(>20 \mathrm{~J} / \mathrm{m}^{2}\right.$ as measured by double cantilever beam test). In this study, the sol-gel coatings were composed of hybrid O/I silica (based on organoalkoxysilanes and colloidal silica) and designed to favor covalent bonding between the hybrid network and the surface treated PC, hence increasing the contribution of the plastic deformation from the substrate. Interestingly, doublecantilever beam (DCB) tests showed that the coating's adhesion to PC was the same irrespective of the organoalkoxysilanes/ colloidal silica ratio. The versatility of the sol-gel deposition techniques (dip-coating, spray-coating, etc.), together with the excellent mechanical properties and exceptional adherence of this hybrid material to PC should lead to interesting new applications in diverse fields: optical eye-glasses, medical materials, packaging, and so forth.

KEYWORDS: polycarbonate, sol-gel, hybrid silica, elastic properties, adhesion, plasma treatment, double cantilever beam

34 Polycarbonate (PC) is widely used commercially because of its 35 interesting characteristics such as transparency, lightness, high 36 impact resistance, along with an excellent quality/price ratio. 37 However, PC suffers from low scratch resistance and poor 38 stability in humid environment or UV exposure, leading to a 39 decrease in the material's lifetime and to the release of 40 Bisphenol A, a molecule highly suspected to be detrimental for 41 human health. As of today, two different approaches have been 42 mainly considered to mitigate these issues: formulating PC43 based copolymers, ${ }^{1}$ or modifying the PC surface with a 44 protective coating. $^{2-6}$ While the latter approach is more 45 challenging, it provides a very attractive solution to the 46 industry if the adhesion, the bulk mechanical properties, and 47 the barrier properties of such coatings could be precisely 48 controlled. Therefore, the research in this field has mainly 49 focused on the optimization of the coating's bulk mechanical properties. In this regard, hybrid organic/inorganic silica 50 coatings prepared by sol-gel chemistry have received lots of 51 attention because of the possibility to enhance the mechanical 52 properties through the inorganic part while imparting other 53 specific properties for a given application with the organic 54 functionalities. ${ }^{7}$ The sol-gel route also presents several other 55 advantages such as, the availability of a large library of 56 precursors, implementability with low cost equipment, and 57 compatibility with PC's relatively low glass transition temper- 58 ature $\left(143{ }^{\circ} \mathrm{C}\right)$.

In this paper, highly transparent hybrid silica coatings issued 60 from 3-glycidoxypropyltriethoxysilane (GPTES), tetraethylor- 61 thosilicate (TEOS), and colloidal silica prepared by the sol-gel 62

Received: August 20, 2013

Accepted: October 2, 2013 
63 route under acidic conditions and dip-coated on untreated and 64 plasma pretreated PC are reported. This selection of precursors 65 should ensure good mechanical properties for the bulk due to 66 the silica network ${ }^{8,9}$ as well as an elevated interfacial fracture 67 energy if plastic deformation within the PC could be activated. 68 The effect of the precursor's ratio and the PC pretreatment on 69 the bulk hardness, Young's modulus, and density, along with 70 the adhesive fracture energy are thus investigated. As expected, 71 both the hardness and the elastic modulus measured using 72 nanoindentation and the density measured by X-ray reflectivity 73 increased with increasing inorganic content, that is, colloidal 74 silica. The coatings adhesive fracture energy $\left(G_{c}\right)$ was quantified 75 by a double cantilever beam (DCB) test, a newly adapted 76 technique for polymeric substrates. To the best of our 77 knowledge, it has never been reported for sol-gel hybrid silica 78 films deposited on PC. The $G_{\mathrm{c}}$ values increased from less than 2 $79 \mathrm{~J} / \mathrm{m}^{2}$ to more than $20 \mathrm{~J} / \mathrm{m}^{2}$ when the PC surface was pretreated 80 with a nitrogen based plasma. Moreover, the excellent film 81 adhesive properties are maintained over long time storage as 82 the same $G_{\mathrm{c}}$ values were obtained after aging for 1 year under 83 atmospheric conditions. Surprisingly, the coatings fracture 84 energy was not affected when the colloidal silica content varied 85 from 10 to 50 wt \%. Altogether, these results demonstrate that 86 the bulk and the adhesive properties of such hybrid coatings 87 can be independently controlled. It could be envisioned that 88 with the proper pretreatment, precursors selection and sol-gel 89 conditions, tunable optical, electrical, mechanical, and surface 90 properties could be achieved while preserving the interfacial 91 integrity of the coating to the polymeric substrate.

\section{EXPERIMENTAL METHODS}

93 Coating Preparation. Coatings were prepared by the sol-gel route 94 using TEOS and GPTES as alkoxysilanes and commercially available 95 colloidal silica (Levasil 200E from AKZONOBEL, with an average 96 particles size of $30 \mathrm{~nm}$ ). Solutions with different alkoxysilanes/ 97 colloidal silica weight ratios ranging from $50 / 50$ to $90 / 10$ have been 98 prepared. The coating deposition was realized after $36 \mathrm{~h}$ of sol aging 99 by dip-coating at $1 \mathrm{~mm} / \mathrm{s}$, on both untreated and pretreated PC. 100 Regarding the latter, a $\mathrm{N}_{2} / \mathrm{H}_{2}$ plasma treatment was performed by 101 AcXys Technologies company (atmospheric pressure, $300 \mathrm{~mm} / \mathrm{s}$ flow 102 rate) on the PC surface prior to coating deposition. Atomic force 103 microscopy (AFM) analysis performed after treatment did not indicate 104 any change in terms of surface roughness. Finally, the coated samples 105 were annealed under air in a ventilated oven at $135^{\circ} \mathrm{C}$ for $1 \mathrm{~h}$. Several 106 micrometer-thick coatings were obtained. The coating preparation 107 steps and deposition are fully described in reference 8.

108 Characterization. The density, $\rho$, of the coating was measured by 109 specular X-ray reflectivity (XRR) using a diffractometer (X'Pert Pro 110 MRD, Panalytical, Westborough, MA) with a ceramic X-ray tube $(\lambda=$ $1110.154 \mathrm{~nm}$ ) and high resolution horizontal goniometer (reproducibility $\left.112= \pm 0.0001^{\circ}\right)$. The critical angle, $\theta_{\mathcal{C}}$ from the reflectivity data was 113 obtained from the peak position of $I \times q^{4}$ versus $q$ plot, where $I$ is the 114 reflected X-ray intensity, $q=(4 p / \lambda) \times \sin \theta, \lambda$ is the wavelength, and $\theta$ 115 is the grazing angle of the X-ray beam. The coating density $\rho$ was 116 inferred from the electronic density $\rho_{\mathrm{e}}$ calculated using the equation

$$
\rho_{\mathrm{e}}=\frac{\theta_{\mathrm{c}}}{\lambda} \times \frac{\pi}{r_{\mathrm{e}}} \times \frac{A}{Z} \times N_{\mathrm{A}}
$$

117 where $r_{\mathrm{e}}$ is the classical electron radius, $A$ the atomic mass number, $Z$ 118 the atomic number, and $N_{\mathrm{A}}$ the Avogadro number.

119 Quasi-static nanoindentation measurements were performed on a 120 commercial nanoindenter, Hysitron Model TI-950, with a diamond 121 cube corner (three-sided pyramid) probe of $40 \mathrm{~nm}$ end radius. To 122 eliminate adsorbed moisture that could complicate measurements of 123 mechanical properties, nanoindentation was carried out under a 124 positive pressure of dry nitrogen in the closed indenter enclosure.
Freshly loaded samples were allowed to equilibrate with dry nitrogen 125 for at least $12 \mathrm{~h}$ that also allows for thermal equilibrium. The cube 126 corner probe was calibrated on a quartz sample with a modulus of 70127 $\mathrm{GPa}$. As the probe was indenting the sample, both contact depth $(h) 128$ and applied load $(P)$ were monitored. Seven different loads ranging 129 from $7 \mathrm{uN}$ to $25 \mathrm{uN}$ with 7 runs per load were carried out on each 130 sample. At the maximum indentation depth, the load was kept 131 constant for $5 \mathrm{sec}$. A load versus contact depth curve was then 132 generated from the collected data. The reduced Young's modulus $E_{\mathrm{r}} 133$ and hardness $H$ were further calculated based on their relationship 134 with the contact area $A_{c}$ and the sample stiffness $S$ using the following 135 equations:

$$
\begin{aligned}
& H=\frac{P_{\max }}{A_{\mathrm{c}}} \\
& E_{\mathrm{r}}=\frac{1}{\beta} \frac{\sqrt{\pi}}{2} \times \frac{S}{\sqrt{A_{\mathrm{c}}}}
\end{aligned}
$$

The effective contact area $A_{c}$ was calculated from the contact depth 137 and the tip geometry using the Oliver and Pharr method. ${ }^{10}$ The 138 stiffness was obtained from the slope of the unloading curve $(\partial P) / 139$ $(\partial h)$.

140

The Young's modulus, $E_{\mathrm{f}}$, was then calculated from the reduced 141 modulus $E_{\mathrm{r}}$, taking into account elastic displacements from both the 142 film and the indenter, using the equation

$$
\frac{1}{E_{\mathrm{r}}}=\frac{\left(1-v_{\mathrm{i}}^{2}\right)}{E_{\mathrm{i}}}+\frac{\left(1-v_{\mathrm{f}}^{2}\right)}{E_{\mathrm{f}}}
$$

where $E_{\mathrm{i}}$ is the indenter Young's modulus (1140 GPa), $\nu_{\mathrm{i}}$ the indenter 144 poisson's ratio $(0.07)$, and $\nu_{\mathrm{f}}$ the film poisson's ratio (assigned as 0.25 ). 145

The coatings adhesion energy on PC was quantified using the 146 symmetric Double Cantilever Beam (DCB) test. The specimens were 147 prepared by bonding a blank (uncoated) substrate of $2 \mathrm{~mm}$ - thickness 148 onto a coated substrate of the same thickness. The in-plane 149 dimensions of the specimen were $9 \mathrm{~mm} \times 70 \mathrm{~mm}$. The fracture 150 tests were conducted on a micromechanical adhesion test system 151 (DTS Delaminator Test System, DTS Company, Menlo Park, CA) in 152 displacement control mode. The specimens were loaded at a 153 displacement rate of $5 \mu \mathrm{m} / \mathrm{sec}$ in tension to produce controlled 154 crack growth, followed by unloading. The load was measured 155 simultaneously and the adhesion energy $G_{c}\left(\mathrm{~J} / \mathrm{m}^{2}\right)$ was calculated 156 from the critical value of the strain energy release rate using the 157 Kanninen corrected equation ${ }^{11}$

$$
G_{\mathrm{c}}=\frac{12 \times P_{\mathrm{c}}^{2}}{E \times B^{2} \times h} \times\left(\frac{a}{h}+0.64\right)^{2}
$$

where $P_{c}$ is the load when the load-displacement curve deviated from 159 linearity until initial crack extension, $E$ the plane strain Young's 160 modulus of the substrate, B the substrate width, $a$ the crack length, and 161 $h$ the substrate thickness.

X-ray photoelectron spectroscopy (XPS) [Physical Electronics Inc, 163 Chanhassen, $\mathrm{MN}$ ] was used to characterize the atomic composition of 164 the DCB fracture surfaces throughout the bulk. An Al-K $\alpha(1486 \mathrm{eV}) 165$ $\mathrm{X}$-ray source with a spot size of $\sim 1 \mathrm{~mm}$ was used in conjunction with 166 an argon ion beam to sputter off the material at a rate of $4 \mathrm{~nm} / \mathrm{min}$ for 167 the silica coatings, with the setting of $1 \mathrm{kV}, 0.5 \mu \mathrm{A}$, and $1 \mathrm{~mm} \times 1 \mathrm{~mm} 168$ sputter spot. The angle between the detector and the sample surface 169 was $45^{\circ}$. The scan range for the binding energy was 0 to $1000 \mathrm{eV}$. 170

\section{RESULTS AND DISCUSSION}

Four different sol-gel solutions with alkoxysilanes/colloidal 172 silica weight ratios of 50/50,70/30, 80/20, and 90/10 were 173 studied. The alkoxysilanes contribution comes from a mixture 174 of GPTES and TEOS with a constant TEOS/GPTES molar 175 ratio of 1.65. Regarding the coatings' thermal treatment, the 176 low annealing temperature of the samples (set at $135{ }^{\circ} \mathrm{C}$ to stay 177 below the $T_{\mathrm{g}}$ of PC) should prevent the formation of highly 178 
179 densified silica. Therefore, pre-condensed colloidal silica was 180 added to the solutions to strengthen the final coating. As 181 described previously, ${ }^{8}$ sol-gel solutions were aged for $36 \mathrm{~h}$ 182 before deposition, to ensure completion of the hydrolysis 183 reaction while condensation is still at an early stage. ${ }^{12}$ This 184 should lead to maximum bonding between the coating and the 185 substrate during film deposition and curing.

186 To assure the substrate's integrity over time, it was highly 187 important to assess the coatings bulk properties with regards to 188 raw PC, and also to evaluate the coatings' adhesion to the 189 substrate, a critical component of the coating's lifetime. Those 190 two characteristics were studied separately. The bulk 191 mechanical properties (Young's modulus and hardness) and 192 density were measured by nanoindentation, and by X-ray 193 reflectivity, respectively. The coatings fracture energy was 194 obtained from symmetric DCB tests.

195 Bulk Properties. First, we measured the coatings densities 196 by X-ray reflectivity as a function of the colloidal silica content 197 (Figure 1). In the range of 10 to 50 wt \% colloidal silica, the

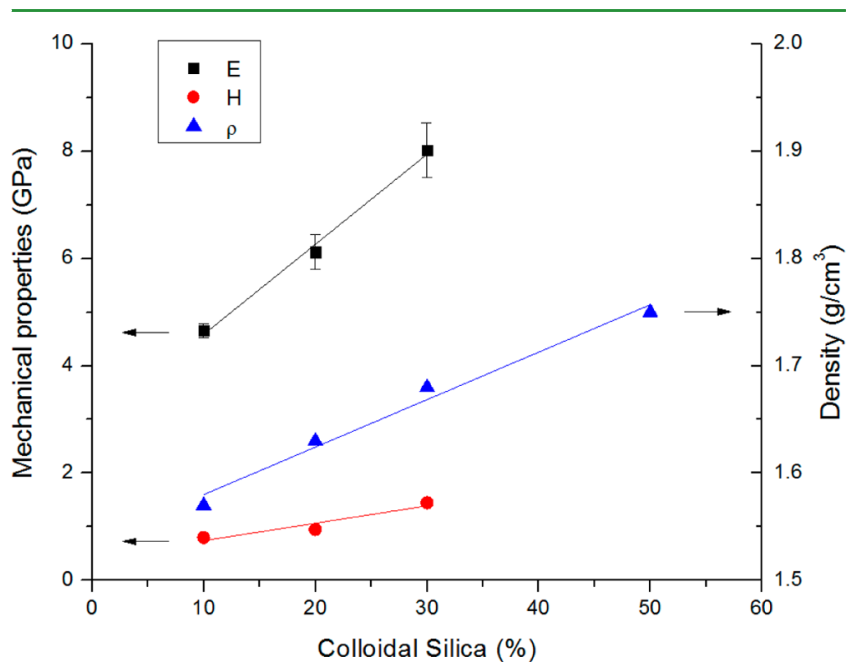

Figure 1. Coatings Young's modulus $(E)$, hardness $(H)$, and density $(\rho)$ as a function of colloidal silica percentage as measured by nanoindentation. Hardness standard deviation was always smaller than $0.1 \mathrm{GPa}$ and is not represented here. Pure silica Young's modulus hardness and density from literature respectively are $72 \mathrm{GPa}, 8 \mathrm{GPa}$, and $2.2 \mathrm{~g} / \mathrm{cm}^{3}$.

198 density increased linearly from $1.57 \mathrm{~g} / \mathrm{cm}^{3}$ to $1.75 \mathrm{~g} / \mathrm{cm}^{3}$. As 199 expected, the addition of pre-densified silica nanoparticles leads 200 to a significant change in film bulk properties. Interestingly, by 201 extrapolating the density data to $100 \mathrm{wt} \%$ colloidal silica, one 202 would obtain a density of $1.94 \mathrm{~g} / \mathrm{cm}^{3}$, a value close to the one 203 of dense silica coatings $\left(2.2 \mathrm{~g} / \mathrm{cm}^{3}\right)$ deposited by gas phase 204 deposition techniques. ${ }^{13}$ The results above indicate that the 205 intrinsic density of the nanoparticles is around $1.94 \mathrm{~g} / \mathrm{cm}^{3}$ and 206 that they are well dispersed throughout the main bulk of the 207 film. Moreover, the absence of porosity, as indicated by 208 ellipsometric measurements, ${ }^{8}$ suggests that the intimate mixing 209 of the nanoparticles within the hybrid network was successfully 210 achieved.

211 Next, nanoindentation experiments were conducted on the 212 different coatings to study the influence of the silica 213 nanoparticle loading on the bulk Young's modulus and 214 hardness (Figure 1). The contact depth measured at the 215 different loads for coatings with up to $30 \mathrm{wt} \%$ silica 216 nanoparticles was always smaller than a tenth of the total film thickness $(2-3 \mu \mathrm{m})$, minimizing the substrate effect. ${ }^{14} 217$ Conversely, nanoindentation data indicated a strong substrate 218 contribution for $50 \mathrm{wt} \%$ colloidal silica content coatings, 219 because of the lower film thickness $(1.2 \mu \mathrm{m})$ combined with 220 the substrate plasticity and consequently they are not reported 221 here. Both Young's modulus and hardness were found to 222 increase when the colloidal silica percentage was varied from 10223 to 30 wt \%. The Young's modulus almost doubled, increasing 224 from $4.7 \mathrm{GPa}$ to $8.0 \mathrm{GPa}$ while the hardness changed by more 225 than $80 \%$, from $0.8 \mathrm{GPa}$ to $1.5 \mathrm{GPa}$. In comparison, the 226 Young's modulus and hardness of PC are respectively $2.5 \mathrm{GPa} 227$ and $0.17 \mathrm{GPa}^{15}$ These data clearly demonstrate the mechanical 228 benefits obtained by depositing such coatings onto PC. These 229 values are also similar to the ones reported for silica particle 230 doped sol-gel coatings on different substrates. Depending upon 231 both the silica particle content and the alkoxysilanes nature, 232 moduli between 1 and $15 \mathrm{GPa}$ and hardness of 0.2 to $2 \mathrm{GPa} 233$ have been obtained by nanoindentation. ${ }^{2,3,16-21}$ Altogether, 234 this confirms that the addition of pre-densified silica enables the 235 toughening of a broad range of organosilicate films. Moreover, 236 the linear increase of the film mechanical properties is in good 237 agreement with the one observed for the density over the same 238 colloidal silica range. These results support that the silica 239 nanoparticles are homogeneously distributed within the hybrid 240 network. Finally, it demonstrates that such a toughening 241 strategy can be applied when low thermal requirements need to 242 be satisfied.

Film/PC Interfacial Adhesion. The adhesive fracture 244 energy $\left(G_{c}\right)$ of the various coatings was obtained by symmetric 245 DCB. This technique specifically measures the adhesion 246 between a coating and a substrate independently of any other 247 mechanical characteristics. This is fundamentally different from 248 the scratch test technique where the samples are stressed both 249 normally and tangentially at the same time. In this case, the 250 lower force at which cracking occurs (Lc1) is a function of both 251 bulk mechanical properties and interfacial adhesion. Never- 252 theless, this technique has been widely utilized for the 253 qualitative characterization of protective coatings on PC., 19,22 254 Conversely, DCB was only recently adapted to polymeric 255 substrates, ${ }^{11,23}$ permitting quantitative measurements of the 256 adhesive fracture energy. Coatings with different composition 257 deposited both on untreated and $\mathrm{N}_{2} / \mathrm{H}_{2}$ plasma pretreated PC 258 were studied. The $G_{\mathrm{c}}$ values measured on untreated and plasma 259 treated PC as a function of composition are plotted in Figure 2. $260 \mathrm{f} 2$

All coatings display similar behavior: the plasma treatment 261 leads to a significant increase in $G_{\mathrm{c}}$ from $1-2 \mathrm{~J} / \mathrm{m}^{2}$ to more 262 than $20 \mathrm{~J} / \mathrm{m}^{2}$, and the adhesion of the sol-gel film to the 263 substrate is unaffected by the colloidal silica loading. It is worth 264 noting that the fracture occurred at the hybrid film to PC 265 interface as indicated by the X-ray photoelectron spectroscopy 266 (XPS) surface analysis results shown in Figure 3. The low $267 \mathrm{f} 3$ interfacial fracture energy measured for the pristine PC is not 268 surprising as the hydrophilic coating should have little 269 interaction with the hydrophobic PC surface. In this case, 270 adhesive debonding occurs at low applied stress at the interface 271 and consequently little energy can be dissipated in the PC 272 substrate. After the plasma treatment the PC surface becomes 273 hydrophilic, that is, the water contact angle drops from $82^{\circ}$ to 274 less than $40^{\circ}$. The formation of polar bonds, such as, $\mathrm{C}-\mathrm{OH} 275$ and $\mathrm{C}-\mathrm{NH}_{2}$ has already been evidenced by XPS, ${ }^{8}$ it not only 276 renders the PC surface more hydrophilic but it also most likely 277 leads to covalent bonding with both organic and inorganic 278 moieties from the hybrid network. ${ }^{24}$ The interaction between 279 


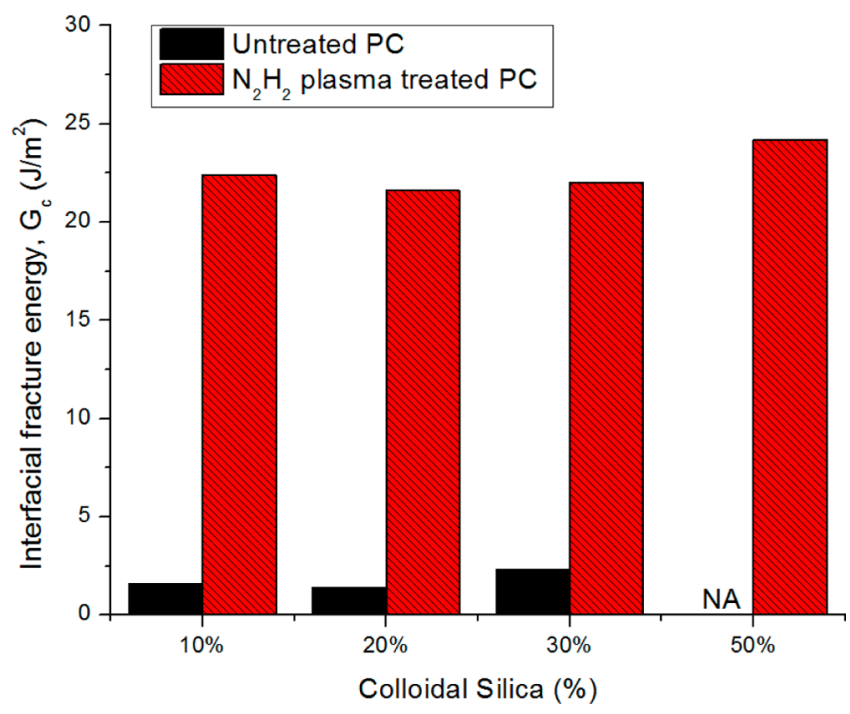

Figure 2. Coatings adhesive fracture energy as a function of colloidal silica ratio on untreated or $\mathrm{N}_{2} / \mathrm{H}_{2}$ plasma treated $\mathrm{PC}$ as measured by DCB.

280 the hybrid coating and the PC is therefore increased. 281 Furthermore, plasma treatments are known to roughen the 282 polymer surface creating a larger contact surface between the 283 two materials. ${ }^{25,26}$ These two factors are responsible for the 10 284 fold increase in interfacial fracture energy after plasma 285 treatment: the higher energy input required to overcome the 286 stronger interaction between the coating and the substrate 287 results in a higher stress state at the vicinity of the crack tip, and 288 more energy is dissipated in the substrate and coating because 289 of plastic deformation. While the plasma treatment time was 290 not optimized for this specific coating, it is unlikely that a low 291 molecular weight layer (LMWL) due to PC over-exposure was formed in our case. Indeed, the presence of a LMWL on PC 292 leads to a rapid decay of the adhesive fracture energy with $G_{c} 293$ values $<10 \mathrm{~J} / \mathrm{m}^{2}$ for silica coatings deposited by atmospheric 294 plasma. $^{11}$

The colloidal silica content seems to have little or no effect 296 on the adhesion to PC. While surprising at first, this can be 297 rationalized if there is no segregation of silica nanoparticles at 298 the interface and if the plastic properties of the hybrid network 299 do not significantly change. It has been shown in the case of 300 polymeric nanoparticles that segregation at the substrate 301 interface occurs with hydrophilic surfaces and is a function of 302 the nanoparticles' loading. ${ }^{27}$ We believe that the use of a water 303 based sol-gel solution minimizes this segregation phenomenon 304 as all the hydrolyzed silicate species will maintain strong 305 interaction with the $\mathrm{Si}-\mathrm{OH}$ surface covered silica nanoparticles 306 after film deposition. This is in good agreement with the XRR 307 and nanoindentation data, which indicated a homogeneous 308 composition throughout the film thickness. XPS depth profiling 309 analysis of the beams after $G_{\mathrm{c}}$ measurement confirmed that the 310 fracture occurred at the film to PC interface and that its 311 composition was identical to the bulk. An example of such 312 profile is shown in Figure 3 for the $30 \mathrm{wt} \%$ loading colloidal 313 silica sample. Despite the high carbon content initially detected 314 (coming from both atmospheric contamination and polymeric 315 residues after fracture) and removed with $30 \mathrm{sec}$ of sputtering, 316 the concentration of carbon, silicon, and oxygen atoms is 317 constant from the fractured interface into the bulk. 318

Regarding plastic deformation of the hybrid network, it can 319 only be influenced by the GPTES amount if polymeric chains 320 are formed through epoxide opening. ${ }^{28}$ Even at $10 \mathrm{wt} \% 321$ colloidal silica loading (i.e. maximum GPTES content), the low 322 $G_{\mathrm{c}}$ value measured on untreated PC indicates that there is little 323 or no hybrid network plastic deformation. In this case, 324 increasing the stiffness of the hybrid network with the addition 325 of more silica nanoparticles would certainly not add plasticity to 326

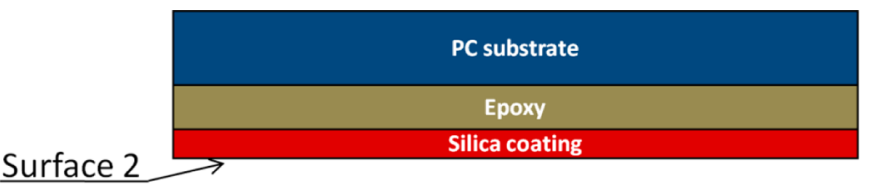

(a)

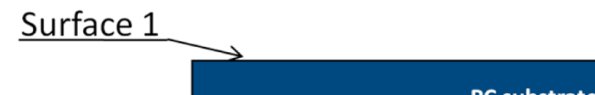

PC substrate
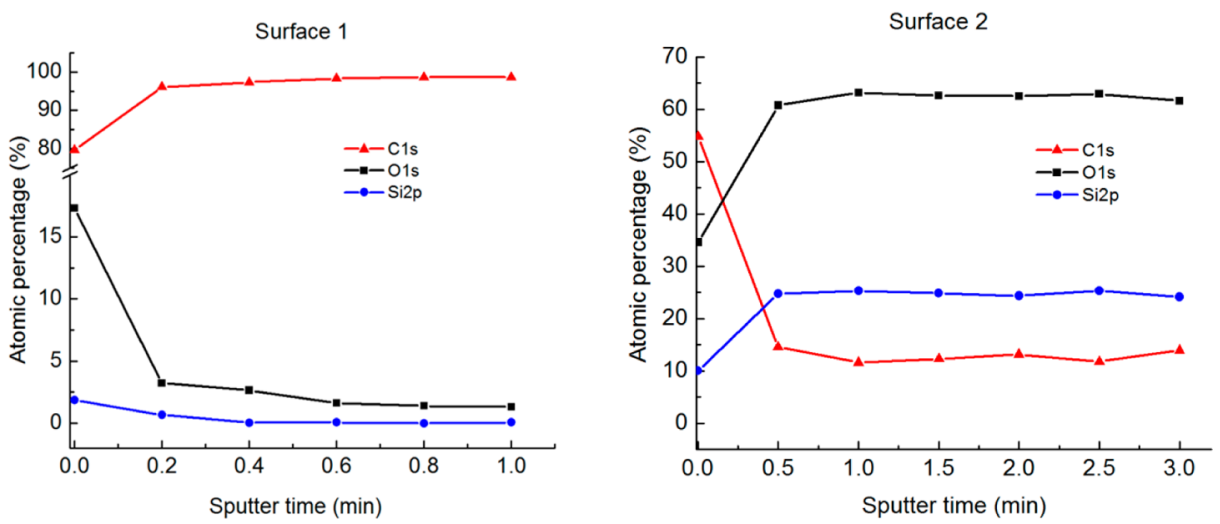

Figure 3. (a) Scheme of ideal XPS analyzed surfaces (after DCB fracture) and (b) XPS depth profile of the interfacial layer between the PC substrate (surface 1 ) and the $30 \mathrm{wt} \%$ loading colloidal silica coating (surface 2 ). 
327 the coating. Conversely, for plasma treated PC, the high $G_{c}$ 328 values measured indicate that plastic deformation has been 329 activated in both the PC substrate and the hybrid network. 330 However, the lack of change in $G_{c}$ values when decreasing the 331 coating organic content suggests that the contribution of the 332 hybrid network plastic deformation is minimal compared to 333 that in PC.

334 Finally, 10, 20, and 30 wt \% colloidal silica loading samples 335 were prepared the same day but their interfacial fracture energy 336 was measured after 1 year interval to probe the robustness of 337 the film towards environmental conditions. The results 338 presented in Table 1 demonstrate that the interfacial fracture

Table 1. Interfacial Fracture Energy Measured in the Wake of Coating Deposition (Test 1) and after Aging for 1 Year (Test 2)

\begin{tabular}{ccc} 
& \multicolumn{2}{c}{$G_{\mathrm{c}}\left(\mathrm{J} / \mathrm{m}^{2}\right)$} \\
\cline { 2 - 3 } colloidal silica \% & test 1 & test 2 \\
10 wt \% & $24.9 \pm 2.1$ & $19.8 \pm 2.9$ \\
20 wt \% & $20.2 \pm 2.1$ & $23.0 \pm 2.4$ \\
30 wt \% & $20.1 \pm 2.8$ & $23.9 \pm 2.5$
\end{tabular}

339 energy is not affected by the coating aging time. Consequently, 340 these sol-gel hybrid films could be potential candidates for 341 development toward industrial applications.

\section{$342 \square$ CONCLUSION}

343 In conclusion, we have demonstrated that the bulk properties 344 and the interfacial adhesion of PC protective coatings based on 345 sol-gel chemistry can be independently controlled. The use of 346 pre-condensed silica nanoparticles to toughen the hybrid 347 network while respecting the thermal requirements due to 348 the low glass transition temperature of the PC substrate was 349 successfully achieved. DCB was used for the first time to 350 quantitatively measure the interfacial fracture energy of sol-gel 351 hybrid silica films deposited on PC. For these films, the 352 adhesion was only a function of the PC plasma surface 353 pretreatment and independent of the silica content. With 354 nanoparticle loadings ranging from 30 to $50 \mathrm{wt} \%$, the Young's 355 modulus was $>8.0 \mathrm{GPa}$ and the adhesive fracture energy $G_{\mathrm{c}}$ was 356 found to be $>20 \mathrm{~J} / \mathrm{m}^{2}$. These values remained unchanged after 357 aging at ambient conditions for 1 year, making this protective 358 coating very attractive for further development. The protective 359 coating mechanical properties are currently under investigation 360 under environmental conditions known to degrade PC: UV 361 exposure and high humidity. If the correlation between these 362 properties and PC degradation can be established, it might 363 provide a novel way to assess BPA release in applications where 364 PC toxicity is a concern.

\section{AUTHOR INFORMATION}

\section{Corresponding Authors}

367 *E-mail: dauskardt@stanford.edu (R.H.D.).

368 *E-mail: toury@univ-lyon1.fr (B.T.).

369 *E-mail: gdubois@us.ibm.com (G.D.).

370 Notes

371 The authors declare no competing financial interest.

\section{$372 \square$ ABBREVIATIONS}

373 PC, polycarbonate; O/I, organic/inorganic; DCB, double374 cantilever beam; GPTES, 3-glycidoxypropyltriethoxysilane;
TEOS, tetraethylorthosilicate; XRR, X-ray reflectivity; XPS, 375 $\mathrm{X}$-ray photoelectron spectroscopy; $\mathrm{Tg}$, glass transition temper- 376 ature; LMWL, low molecular weight layer

\section{REFERENCES}

(1) Fabbri, P.; Leonelli, C.; Messori, M.; Pilati, F.; Toselli, M.; 379 Veronesi, P.; Morlat-Therias, S.; Rivaton, A.; Gardette, J. L. J. Appl. 380 Polym. Sci. 2008, 108, 1426-1436.

(2) Wouters, M. E. L.; Wolfs, D. P.; van der Linde, M. C.; Hovens, J. 382

H. P.; Tinnemans, A. H. A. Prog. Org. Coat. 2004, 51, 312-320. 383

(3) Soloukhin, V. A.; Posthumus, W.; Brokken-Zijp, J. C. M.; Loos, J.; 384 de With, G. Polymer 2002, 43, 6169-6181.

(4) Keranen, M.; Gnyba, M.; Raerinne, P.; Kololuoma, T.; Maaninen, 386 A.; Rantala, J. T. J. Sol-Gel Sci. Technol. 2004, 31, 369-372. 387

(5) Su, C. H.; Lin, C. R.; Chang, C. Y.; Hung, H. C.; Lin, T. Y. Thin 388 Solid Films 2006, 498, 220-223. 389

(6) Li, C. H.; Wilkes, G. L. J. Inorg. Organomet. Polym. 1997, 7, 203- 390 216.

(7) Sanchez, C.; Julian, B.; Belleville, P.; Popall, M. J. Mater. Chem. 392 2005, 15, 3559-3592.

(8) Lionti, K.; Toury, B.; Boissière, C.; Benayoun, S.; Miele, P. J. Sol- 394 Gel Sci. Technol. 2013, 65, 52-60.

(9) Wu, L. Y. L.; Chwa, E.; Chen, Z.; Zeng, X. T. Thin Solid Films 396 2008, 516, 1056-1062.

(10) Oliver, W. C.; Pharr, G. M. J. Mater. Res. 1992, 7, 1564-1583. 398

(11) Cui, L.; Ranade, A. N.; Matos, M. A.; Pingree, L. S.; Frot, T. J.; 399 Dubois, G.; Dauskardt, R. H. ACS Appl. Mater. Interfaces 2012, 4, 400 6587-6598.

(12) Livage, J.; Sanchez, C. J. Non-Cryst. Solids 1992, 145, 11-19. 402

(13) Volksen, W.; Miller, R. D.; Dubois, G. Chem. Rev. 2010, 110, 403 56-110.

(14) Veprek, S.; Veprek-Heijman, M. G. J.; Karvankova, P.; 405 Prochazka, J. Thin Solid Films 2005, 476, 1-29. 406

(15) Benitez, F.; Martinez, E.; Galan, M.; Serrat, J.; Esteve, J. Surf. 407 Coat. Technol. 2000, 125, 383-387.

(16) Zheng, C.; Lin, A. m.; Zhen, X.; Feng, M.; Huang, J.; Zhan, H. 409 Opt. Mater. 2007, 29, 1543-1547. 410

(17) Chen, Z.; Wu, L. Y. L.; Chwa, E.; Tham, O. Mater. Sci. Eng., A 411 2008, 493, 292-298. 412

(18) Robertson, M. A.; Rudkin, R. A.; Parsonage, D.; Atkinson, A. J. 413 Sol-Gel Sci. Technol. 2003, 26, 291-295.

(19) Han, Y.-H.; Taylor, A.; Knowles, K. M. Surf. Coat. Technol. 415 2009, 203, 2871-2877.

(20) Etienne, P.; Sempere, R. Verre 1998, 4, 2-10. 417

(21) Ferchichi, A.; Calas-Etienne, S.; Smaihi, M.; Etienne, P. J. Non- 418 Cryst. Solids 2008, 354, 712-716. 419

(22) Hwang, D. K.; Moon, J. H.; Shul, Y. G.; Jung, K. T.; Kim, D. H.; 420 Lee, D. W. J. Sol-Gel Sci. Technol. 2003, 26, 783-787. 421

(23) Kamer, A.; Larson-Smith, K.; Pingree, L. S. C.; Dauskardt, R. H. 422 Thin Solid Films 2011, 519, 1907-1913.

(24) Innocenzi, P.; Kidchob, T.; Yoko, T. J. Sol-Gel Sci. Technol. 424 2005, 35, 225-235.

(25) Gonzalez, E. I.; Hicks, R. F. Langmuir 2010, 26, 3710-3719. 426 (26) Tang, S.; Choi, H. S. J. Phys. Chem. C 2008, 112, 4712-4718. 427 (27) Ong, M. D.; Volksen, W.; Dubois, G.; Lee, V.; Brock, P. J.; 428 Deline, V. R.; Miller, R. D.; Dauskardt, R. H. Adv. Mater. 2008, 20, 429 3159-3164.

(28) Brusatin, G.; Innocenzi, P.; Guglielmi, M.; Babonneau, F. J. Sol- 431 Gel Sci. Technol. 2003, 26, 303-306. 